\title{
laboratory simulation on drifting of hazardous chemical substance
}

\author{
Xing Wang ${ }^{1,2}$, Lai Wei ${ }^{1, *}$, Xiuren $\mathrm{Li}^{3}$,Fan Yang ${ }^{1}$,Ying Liu ${ }^{1}$, Chunhui Wang ${ }^{1}$, Yunlong Liu ${ }^{1}$ \\ ${ }^{1}$ North China Sea Environmental Monitoring Center, State Oceanic Administration, Qingdao, China \\ ${ }^{2}$ Shandong Provincial Key Laboratory of Marine Ecology and Environment \& Disaster Prevention and Mitigation, Qingdao, China \\ ${ }^{3}$ College of Oceanic and Atmospheric Sciences, Ocean University of China,Qingdao, China
}

\begin{abstract}
The continuously increase of hazardous chemicals transportation leads to a high risk of chemicals leakage. Researches on drifting of chemical substances are of vital importance in damage reducing. Laboratory simulation on drifting of hazardous chemical substance carried out inside a wave tank at the Shandong Provincial Key Laboratory. Different environmental conditions (wind, wave, etc.) were simulated in the wave tank to find out the influence of these factors on substance drifting and diffusion. To identify the difference between hazardous substance, floating ball and dyed petroleum oil were used to simulate solid and liquid floating hazardous chemical substance. The result revealed that wave can improve diffusion, the diffusion speed varies with wave height. Wind can drive surface substance, the drifting coefficient ranges from $2.1 \%$ to $3.0 \%$, while liquid drifting coefficient is relatively larger. The laboratory results provide a basis for the study on the drifting and diffusion of hazardous chemicals at sea. Meanwhile, the coefficient could be applied as a correction in numerical models to improve prediction accuracy.
\end{abstract}

\section{Introduction}

With the development of chemical engineering industry, the growing sea transportation of hazardous chemical substance leads to a higher frequency of leaking accidents. These accidents had severe influence on ocean environment as well as financial loss. On Jan 6, 2018, tanker "Sanchi" had a collision in the East China Sea. Eight days later, it sank with 111 kilotons of condensate oil. The poisonous leaked oil led to the deaths of countless sea animals[1]. Pollution treatment is becoming one of the research focuses currently.

To reduce pollution damage, determine the location of leaking substance is necessary. Numerical model is a low-cost method to predict the position of leaking substance. Existing oil spilling prediction model can provide comparatively accurate calculation result[2,3], while the research on other types of hazardous chemicals is far from satisfactory. According to the "RCRA Hazardous Wastes"[4], more than 1300 kinds of hazardous wastes have high frequency of leakage. Therefore, it is necessary to exploit new models on other kinds of hazardous wastes.

A key to build up a numeric model is to determine the critical parameter, like wind-induced and currentinduced drifting coefficient as well as wave induced mixing. Temperature could speed up molecular movement, thus contribute to diffusion[5]. Waveinduced turbulence will introduce mixing[6], which will dramatically increase chemical substance diffusion. Wind and current can drive substance drifting[7].
Laboratory simulation is an effective method to figure out the effect of different factors.

Recent researches mainly focus on numerical simulation, only minor studies are related to laboratory work. Cong and Zhu studied sediment transport under the influence of wave and tide, providing a new sediment concentration vertical distribution function[8]. Zhao et al used salt water as a simulation of hazardous wastes with same density to study the horizontal diffusion distribution characteristics, offering parameters for environmental pollution mathematical model[9]. Song utilized an ecological environment simulated wave tank to seek out the attenuation coefficient of hazardous wastes[10].

In this work, laboratory research were carried out to increase the accuracy of numerical prediction, thus reducing the environmental damage. The drifting and diffusion of hazardous chemicals (or its simulant) under different environmental conditions were observed. the main parameters were extracted from observed result could be used in improve numerical models while the transportation characteristic could provide basis for drifting and diffusion researches at sea.

\section{Experiment design}

The experiments were performed inside a wave tank at the Shandong Provincial Key Laboratory of Marine Ecology and Environment \& Disaster Prevention and Mitigation, Qingdao. The wave tank was $32 \mathrm{~m}$ in length, $0.8 \mathrm{~m}$ in width, and $2 \mathrm{~m}$ in height and was made of

\footnotetext{
* Corresponding author: weilai198911@163.com
} 
corrosion-resistant steel with a glass inspection window on the side. The tank was equipped with a mechanical wave maker that can generate regular waves or breaking waves with a height of $0-50 \mathrm{~cm}$ and a period of $0.5-5 \mathrm{~s}$. The matched current simulation system can simulate a uniform current field with a velocity of $0-15 \mathrm{~cm} / \mathrm{s}$. Additionally, a wind simulation system consist of fan and plastic cover was added. The plastic cover fixed the top of wave tank to form a stable wind channel and reduce wind energy loss. A fan was placed at the east end of wave tank to blow wind, the practical maximum wind speed can reach $5 \mathrm{~m} / \mathrm{s}$.

Considering the specialty of hazardous chemical substance, floating objects and dyed petroleum oil were used to simulate solid and liquid floating hazardous chemical substance, respectively.

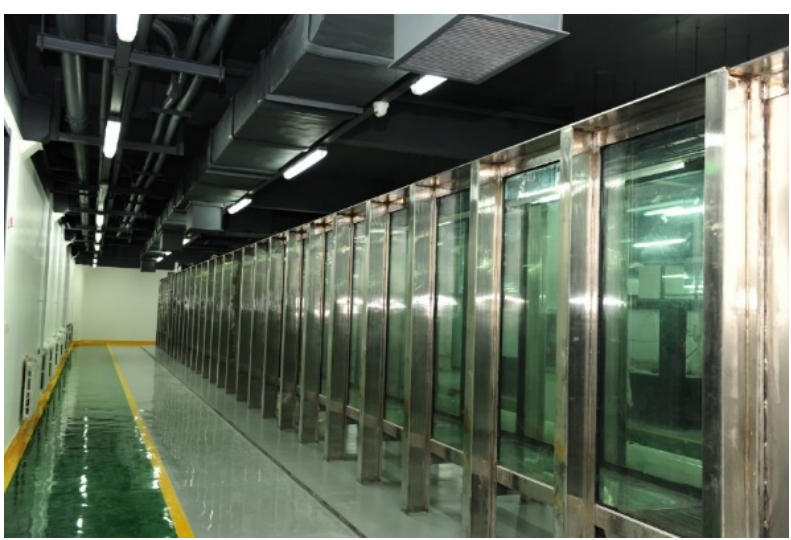

Fig. 1. Part of the wave tank

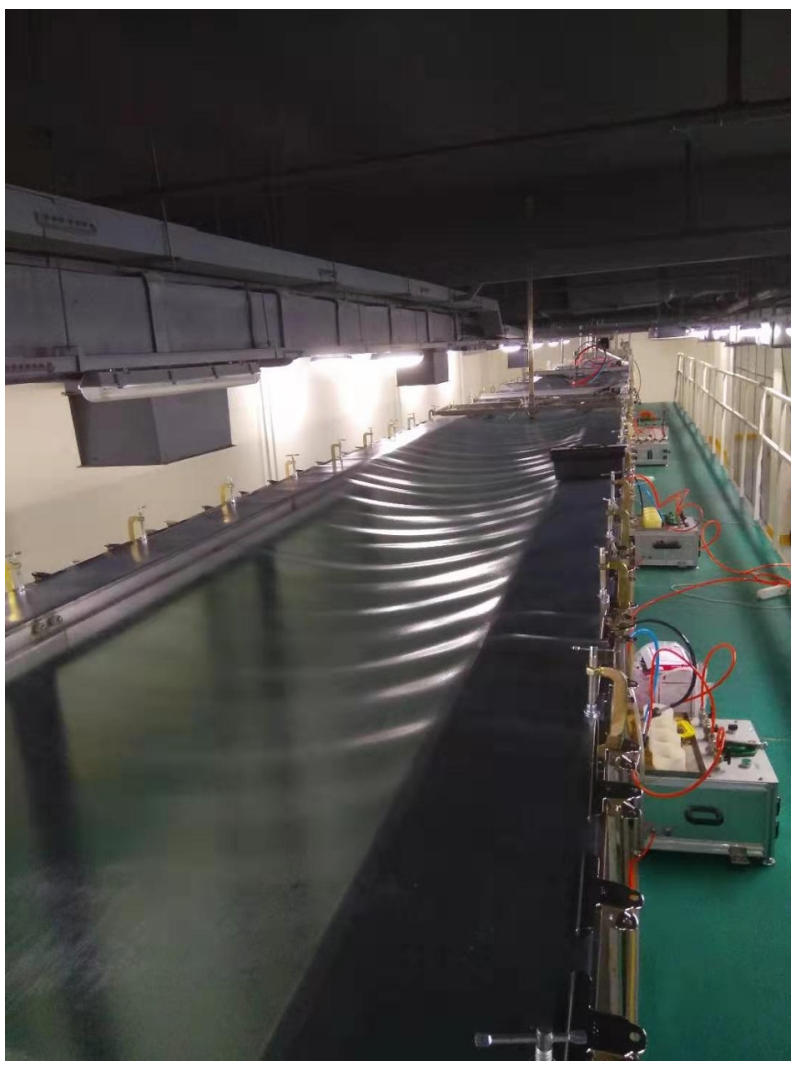

Fig. 2. Newly installed cover
Various wind speed and current speed were tested to find out the coefficient, the practical wind speed decided by the frequency of fan and section from water surface to plastic cover. In the experiment, wind speed was measured with anemometer, hazardous chemical substance simulant was introduced into wave tank after wind field stabled (about 3 minute).

Wave generated with a mechanical wave maker, 3 conditions of wave with different wave height $(10 \mathrm{~cm}$, $20 \mathrm{~cm}, 30 \mathrm{~cm}$ ) were measure with one condition without wave as a contrast. Wave height and period could be controlled by computer connected to wave maker, wave condition measured with wave gauge to make sure the practical wave match the setting.

For better simulation, the tank was filled with $1.3 \mathrm{~m}$ of seawater obtained from Jiaozhou Bay. Cameras were used to record the movement of hazardous chemical substance, several reference gauges were placed at the side of the wave tank to help calculate the velocity of hazardous chemical substance. To get better contrast, the petroleum oil was dyed with oil-soluble red stain (Juents B664789) of $1 \mathrm{~g}$ per $200 \mathrm{ml}$ of oil, the floating wooden objects were also painted red.

\section{Results \& Discussion}

Amount of factors could influence the spread of hazardous chemical substance. Higher temperature can speed up the diffusion, wave can increase the mixing of chemicals and water. Wind and current can drive chemicals drift swiftly. To identify the location of leaking hazardous chemical substance, the drifting coefficient of wind and current is necessary.

\subsection{Effect of wind field}

Floating objects and dyed petroleum oil were used to simulate solid and liquid float hazardous chemical substance. Surface wind-driving current present under the influence of wind, the speed of wind-driving current was identically measured with ADV. In actual experiments, floating objects usually transported to the side of wave tank, the interaction between objects and wave tank will decrease drifting speed. Only result of spherical object was chosen as spherical object had minor interaction.

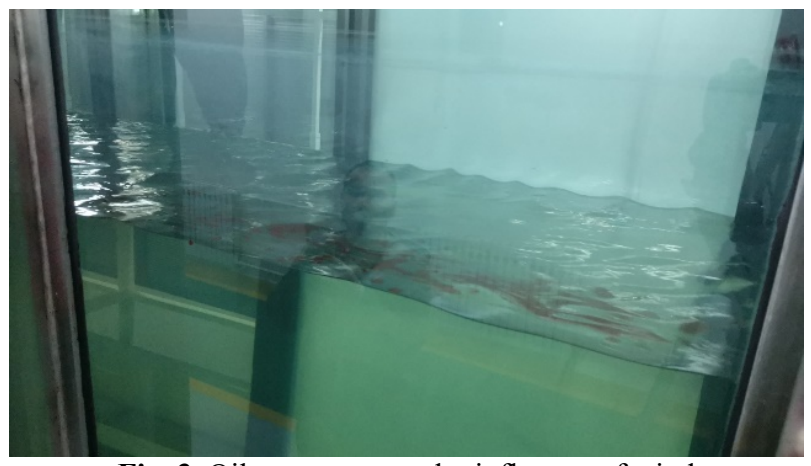

Fig. 3. Oil movement under influence of wind 
Hazardous chemical substance moved downstream with wind. The velocity of hazardous chemical substance is larger than wind-driving current but less than wind speed. Under same wind speed, liquid drifting velocity was larger than solid drifting velocity, and both velocity increase with wind speed. The result showed in table 1 .

The result illustrated that the average solid drifting coefficient is $2.2 \%$, the average liquid drifting coefficient is $2.9 \%$. In the past studies, Kuang et al analyzed the field drifting trajectory data from south China sea joint search-and-rescue exercises, regarding that for dummy model (solid substance), the drifting coefficient is $1.7 \%[11]$. Li et al studied drifting coefficient of green tide alga, giving the drifting coefficient of $0.015[12]$. Based on the experiment on the

Table 1. drifting coefficient of solid and liquid substance

\begin{tabular}{|c|c|c|c|c|c|c|}
\hline $\begin{array}{c}\text { Fan } \\
\text { frequency }\end{array}$ & $\begin{array}{c}\text { Wind speed } \\
(\mathrm{m} / \mathrm{s})\end{array}$ & $\begin{array}{c}\text { Current } \\
\text { speed } \\
(\mathrm{cm} / \mathrm{s})\end{array}$ & $\begin{array}{c}\text { Ball } \\
\text { Velocity } \\
(\mathrm{cm} / \mathrm{s})\end{array}$ & $\begin{array}{c}\text { Oil } \\
\text { velocity } \\
(\mathrm{cm} / \mathrm{s})\end{array}$ & $\begin{array}{c}\text { Solid drifting } \\
\text { coefficient } \\
(\%)\end{array}$ & $\begin{array}{c}\text { Liquid drifting } \\
\text { coefficient } \\
(\%)\end{array}$ \\
\hline 50 & 3.90 & 0.82 & 9.13 & 12.76 & 2.1 & 3.1 \\
\hline 50 & 3.90 & 0.82 & 9.54 & 12.91 & 2.2 & 3.1 \\
\hline 50 & 3.90 & 0.82 & 9.02 & 12.65 & 2.1 & 3.0 \\
\hline 40 & 3.32 & 0.68 & 7.78 & 10.30 & 2.1 & 2.9 \\
\hline 40 & 3.32 & 0.68 & 7.73 & 10.06 & 2.1 & 2.8 \\
\hline 40 & 3.32 & 0.68 & 7.76 & 10.46 & 2.1 & 2.9 \\
\hline 30 & 2.44 & 0.46 & 5.97 & 7.34 & 2.3 & 2.8 \\
\hline 30 & 2.44 & 0.46 & 6.26 & 7.42 & 2.4 & 2.9 \\
\hline 30 & 2.44 & 0.46 & 5.75 & 7.37 & 2.2 & 2.8 \\
\hline
\end{tabular}

No

wave

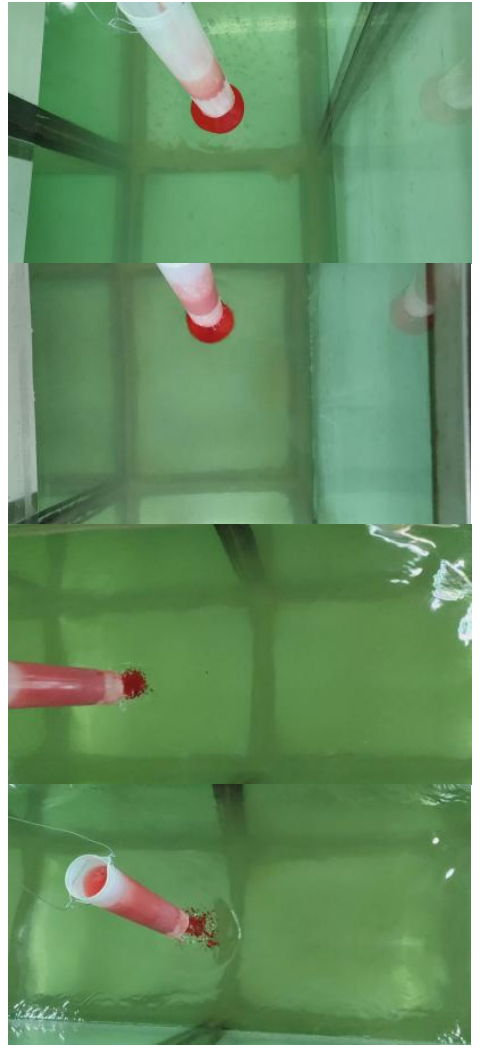

Release time

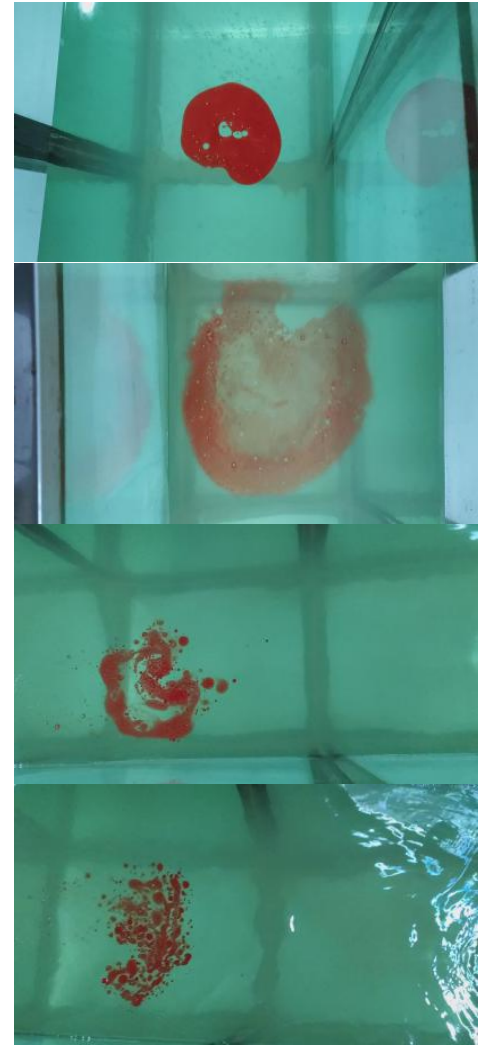

$5 \mathrm{~s}$ after release

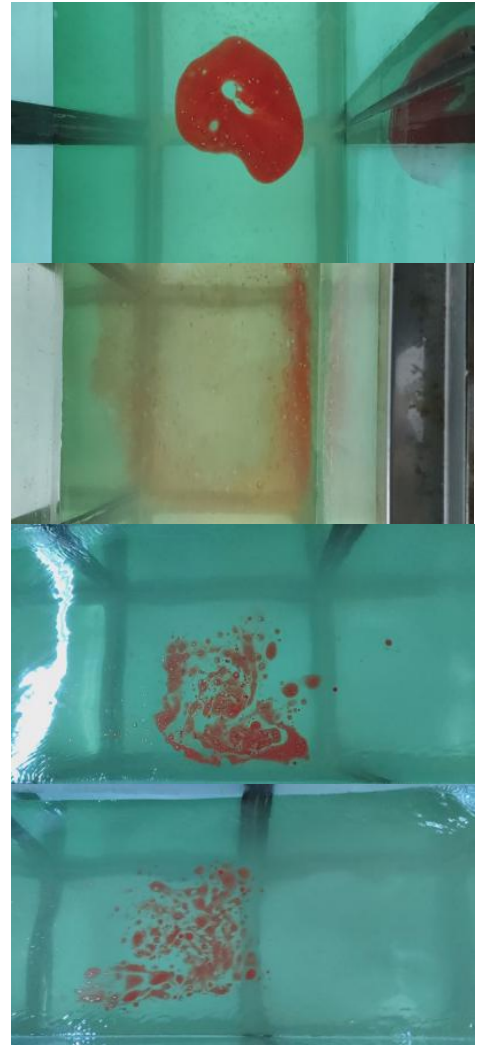

10 s after release

Fig. 4. Oil dispersion under different wave conditions 
sea, Du et al calculated that the drifting coefficient for oil is $0.027[13]$. Ji and Chen calculated a result of 0.02[7]. Considering those studies, the drifting coefficient should ranging from $2.1 \%$ to $3.0 \%$, varies with the density and characteristic of substance.

\subsection{Effect of wave}

Wave can introduce mixing, thus accelerate chemical diffusion. Dyed petroleum oil used to identify the effect of wave on hazardous chemical substance, the oil was restricted in a plastic cylinder located in the middle of wave tank, $0.4 \mathrm{~m}$ from wave tank boundary. A camera placed right above release spot to record oil movement.

Under the influence of wave, oil dispersed into small oil droplets, and will become difficult to observe as they spread. This experiment record the time when the oil reached the boundary of wave $\operatorname{tank}(0.4 \mathrm{~m})$ as the diffusion speed under the influence of wave. The result illustrated that wave can accurate diffusion speed, but with the increasing of wave height, the diffusion speed showed a decrease, but still faster than no wave condition.

Table 2. oil diffusion speed under different wave conditions

\begin{tabular}{|c|c|c|c|c|}
\hline $\begin{array}{c}\text { Wave height } \\
(\mathrm{cm})\end{array}$ & 0 & 10 & 20 & 30 \\
\hline $\begin{array}{c}\text { diffusion } \\
\text { time (s) }\end{array}$ & 23 & 6 & 11 & 12 \\
\hline $\begin{array}{c}\text { diffusion } \\
\text { speed (cm/s) }\end{array}$ & 1.74 & 6.67 & 3.64 & 3.33 \\
\hline
\end{tabular}

\section{Conclusions}

Laboratory simulation can reappear the influence of wind and wave on hazardous substance, but with the restrict of size, the results might have a few differences since the boundary effect of wave tank. Compared with past work, the wind related drifting coefficient of this experiment is dependable.

The results of this experiment illustrated that wave can improve diffusion, while larger wave will decrease substance size and diffusion speed. Wind can drive surface substance, the drifting coefficient ranges from $2.1 \%$ to $3.0 \%$, the average solid drifting coefficient is $2.2 \%$, the average liquid drifting coefficient is $2.9 \%$.

The results provide a basis for the study on the drifting and diffusion of hazardous chemicals at sea. Meanwhile, the coefficient could be applied as a correction in numerical models to improve prediction accuracy. Further research could focus on the difference of drifting coefficient.

\section{Acknowledgments}

This work was supported by National Key R\&D Program of China (No.2016YFC1402404-02).

\section{References}

1. Yin L., Zhang M., Zhang Y., Qiao F., (2018) The long-term prediction of the oil-contaminated water from the Sanchi collision in the East China Sea. Acta Oceanologica Sinica.37(03):1-4

2. Mackay D, Leinonen P J.(1977) Mathematical model of the behavior of oil spills on water with natural and chemical dispersion[R]. Dispersers,

3. Lehr W J. (1996) Modeling the benzene inhalation hazard from spilled oil[J]. Spill Science \& Technology Bulletin, 3(4):199-202.

4. Crowell, Lip M. (2001) RCRA hazardous wastes handbook[J]. Landolt-Börnstein-Group III Condensed Matter, 72(2):235-235.

5. Ye T., Hang J., Zhou J., Lin T., Zong L., Luo C., (2016) Experimental study on characteristics of sewage dilution and dispersion in estuarine and coastal areas[J].Water Resources Protection, 4:131135

6. Wei, L., Guan, C.,Troitskaya, Y., (2018) Laboratory Experiment on Wave Induced Turbulence. J. Ocean Univ. China, 17(04):721-726

7. Ji,R., Chen G., Hu Y., Li Y., (1996) Laboratory model simulation of the oil spill drifting with parameters of current, wind and wave. J. Ocean Univ. China, 26(3):353-359

8. Cong X., Zhu W., Research on sediment transportation pattern under the influence of wave and tide. Zhou Shan, $18^{\text {th }}$ China ocean (shore) engineering academic seminar.

9. Zhao X., LiX., Xu X., wang X., (2012) Experimental Research on Transverse Diffusion Coefficients of Typical Pollutants. Proceedings of Conference on Environmental Pollution and Public Health

10. Song Z., Lu J., Ren X., Wang Z., (2018) Experimental Study on Pollutant Attenuation Law and Its Application in Songyuan River. Water Conservancy Science and Technology and Economy. 24(12)

11. Kuang F., Jing C., Zhang J., (2017) Study of windinduced drift coefficients based on observation and numerical model. Journal of Applied Oceanography 1:41-48

12. Li Y., Pan L., Xiao W., Hu S., Yang H., (2014) Effect of wind on the drifting of green macroalgae in the Yellow Sea. Marine Environmental Science 5:772-776

13. Du W., Liao S., Zhang G., (1986) Offshore experiment on oil drift diffusion . Marine Environmental Science 5(3)53-55 